\title{
O REGIME DE SEPARAÇÃO CONVENCIONAL DE BENS E A NÃO CONCORRÊNCIA DO CÔNJUGE SUPÉRSTITE COM OS DESCENDENTES DO “DE CUJUS”
}

\author{
Ilton Garcia Da Costa ${ }^{1}$ \\ Marcos Paulo dos Santos Bahig Merheb ${ }^{2}$
}

Resumo: O escopo deste trabalho é apresentar os entendimentos do Superior Tribunal de Justiça sobre o regime de separação convencional de bens. Referido Tribunal, em 2009, entendeu pela não concorrência em tal regime, com alteração oposta em 2015. A primeira parte do artigo apresenta conhecimentos sobre os regimes de bens. A segunda parte apresenta o regime de separação convencional de bens e as decisões do Superior Tribunal de Justiça e seu atual posicionamento criticado a luz da autonomia da vontade. Como fonte de pesquisa utilizouse da doutrina, jurisprudência, legislação e periódicos na internet.

Palavras-chave: Regime de bensseparação convencional de bensSuperior Tribuna de justiçaautonomia da vontade

\section{THE REGIME OF CONVENTIONAL SEPARATION OF GOODS AND THE NON-COMPETITION OF THE SUPÉRSTITE SPOUSE WITH THE DESCENDANTS OF "DE CUJUS"}

\begin{abstract}
:
The scope of this work is the understandings of the Superior Court of Justice on the regime of conventional separation of goods. Referred Court in 2009, understood by non-competition in such a scheme, with opposite view in 2015. The first part of the article presents knowledge about the regimes of goods. The second part presents the regime of conventional separation of assets and the decisions of the Superior Court of Justice and its current position criticized in the light of the autonomy of the will. As a source of research was used doctrine, jurisprudence, legislation and periodicals on the internet.
\end{abstract}

Keywords: Regime of goods conventional separation of goodsSuperior Court of justiceautonomy of the will

\footnotetext{
${ }^{1}$ Doutor e mestre em Direito pela PUC-SP. Professor do programa de mestrado e doutorado da UENP-PR.

${ }^{2}$ Mestrando em Ciência Jurídica pela UENP-PR.
} 


\section{INTRODUÇÃO}

No Brasil há quatro regimes típicos de bens, quais sejam: o regime de separação de bens, que se divide em separação obrigatória e convencional; regime de participação final nos aquestos; regime de comunhão universal de bens e; regime de comunhão parcial de bens. Excetuado o regime de comunhão parcial de bens e o de separação obrigatória de bens, todos os demais regimes devem ser escolhidos por meio de pacto antenupcial. Cada um desses regimes de bens possuem regras diferenciadas no momento da dissolução da sociedade conjugal, seja pelo divórcio, seja pela morte, sendo o estudo desta última modalidade a proposta do presente trabalho.

A atual interpretação da doutrina e da jurisprudência, sob a análise da simples literalidade do artigo 1.829, inciso I, combinado com o artigo 1.845 do Código Civil, não restringe a concorrência do cônjuge sobrevivente com os descendentes do “de cujus” em determinados regimes de bens do casamento, tendo em vista a consideração de que o mesmo foi alçado a herdeiro necessário.

A discussão doutrinária e jurisprudencial em relação aos efeitos patrimoniais do casamento após a morte reside na possibilidade ou não da concorrência do cônjuge sobrevivente com os descendentes do falecido.

O Superior Tribunal de Justiça, no ano de 2009, interpretando os dispositivos da matéria, entendeu que o cônjuge sobrevivente casado no regime de separação convencional de bens não concorre com os descendentes do falecido. No entanto, referido Tribunal no ano de 2015 proferiu entendimento em sentido oposto, afirmando que no regime de separação convencional de bens o cônjuge deve concorrer com os herdeiros do “de cujus”.

Os entendimentos do Superior Tribunal de Justiça recebem criticas a favor e contra por parte da doutrina, diante da polêmica causada. É que a interpretação conferida pelo Superior Tribunal de Justiça, doravante influenciará nas decisões das cortes inferiores, repercurtindo na vida daqueles que convolarem núpcias pelo regime de separação convencional de bens.

Não fosse a falta de técnica legislativa, não haveria margem para interpretações divergentes, o que conferiria maior segurança jurídica.

Como informado, o Código Civil de 2002 elevou o cônjuge a qualidade de herdeiro necessário de terceira classe, porém a disciplina conferida ao mesmo no art. 1.829, inciso I, 


\section{O REGIME DE SEPARAÇÃO CONVENCIONAL DE BENS E A NÃO CONCORRÊNCIA DO CÔNJUGE SUPÉRSTITE COM OS DESCENDENTES DO “DE CUJUS”}

deu-lhe tratamento vantajoso, posto que é chamado a concorrer com os herdeiros de primeira e de segunda classe, a depender do regime de bens estabelecido.

O objetivo geral do presente trabalho é discutir os aspectos patrimoniais sucessórios do cônjuge sobrevivente em concorrência com os descendentes do "de cujus" nos diversos regimes de bens, sendo o objetivo específico demonstrar que o cônjuge casado no regime de separação convencional de bens não deve concorrer com os descentes do falecido, posto que esta não foi a intenção da norma, sendo este também a problematização do tema proposto.

Volta-se particular atenção de que o regime da separação convencional de bens é escolhido por meio de pacto antenupcial voluntaria e livremente entre os nubentes, a qual a lei não deve contrariar o que em vida optaram deixar separado. Entendimento diverso certamente viola o princípio da autonomia da vontade.

Para a elaboração e conclusão deste trabalho, optou-se como método de pesquisa o dedutivo, pois por meio da análise da doutrinária e jurisprudência, bem como da legislação pertinente, foi possível teorizar o entendimento quanto a concorrência do cônjuge supérstite nos diversos regimes de bens. A técnica de pesquisa utilizada foi a bibliográfica, legislativa e de decisões judiciais.

\section{DA SUCESSÃO DO CÔNJUGE EM CONCORRÊNCIA COM OS DESCENDENTES NOS DIVERSOS REGIMES DE BENS}

Sabe-se que o atual Código Civil abordou a concorrência do cônjuge sobrevivente tanto com os descendentes quanto com os ascendentes do “de cujus”. No entanto, o presente trabalho tem como finalidade abordar a concorrência do cônjuge apenas com os descendentes do “de cujus”, superficialmente nos diversos regimes de bens, conferindo maior ênfase ao regime de separação convencional de bens, posto este ser o objeto central do tema.

“A concorrência com o descendente permite ao cônjuge receber uma parte de herança que na época do Código Civil de 1916 era destinada exclusivamente ao descendente, independentemente da sua meação” (NETO, 2008, p. 106).

O art. 1.829 do Código Civil afirma que o cônjuge concorrerá com os descendentes do “de cujus”, a depender do regime de bens estabelecido. 
Pela nova disposição legal, o cônjuge herda juntamente com os descendentes, salvo se casado este com o falecido no regime da comunhão universal, ou no da separação obrigatória de bens, ou se, no regime da comunhão parcial, o autor da herança não houver deixado bens particulares. Ou seja, herda o cônjuge se for casado com o regime de separação total (convencional) de bens, participação final nos aquestos ou, não havendo bens particulares, comunhão parcial de bens. (NETO, 2008, p. 128).

“Não é sempre que o sobrevivente recebe um naco do quinhão dos descendentes. Depende do regime de bens que os cônjuges elegeram antes do casamento” (DIAS, 2008, p. 154).

O ordenamento jurídico brasileiro estabeleceu como regimes de bens o regime da comunhão universal, da comunhão parcial, da separação convencional, da separação obrigatória e da participação final nos aquestos.

No que se refere ao regime de comunhão universal de bens, afirma o Código Civil que os bens presentes e futuros serão comunicáveis entre os nubentes, salvo hipóteses especificas de não comunicabilidade. (art. 1.667 e 1.671)

Em tal regime, quando da ocorrência da morte de um dos nubentes, "inexiste direito de concorrência, isso porque o sobrevivente tem o direito de meação sobre todo o acervo patrimonial” (DIAS, 2008, p. 154). A regra é a meação da totalidade dos bens.

A meação em nada tem haver com o direito das sucessões, pois este instituto pertence ao direito de família, posto decorrer do regime de bens escolhido pelos nubentes no momento do matrimonio.

Dentre os direitos patrimoniais do cônjuge, distinguem-se a meação e a herança. Uma coisa é a meação, que decorre do regime de bens e preexiste ao óbito do outro cônjuge, devendo ser apurada sempre que dissolvida a sociedade conjugal. Diversamente, herança é a parte do patrimônio que pertencia ao cônjuge falecido, transmitindo-se aos seus sucessores legítimos ou testamentários (AMORIM, p. 94).

“Meação não é herança, pois os bens comuns são divididos, visto que a porção ideal deles já lhe pertencia” (DINIZ, 2008, p. 124)

O cônjuge supérstite já terá direito à meação e, por essa razão, o legislador entendeu que não haverá o direito à concorrência, já que o sobrevivente terá bens próprios suficientes para garantir o seu sustento. 
Note-se que, pela comunhão universal, os bens que pertencem ao marido em regra, também pertencem à esposa e vice-versa. Assim, estará garantida ao sobrevivente sua meação e seu amparo (TARTUCE, SIMÃO, p. 167).

Portanto, no regime de comunhão universal de bens, o cônjuge sobrevivente não herdará em concorrência com os descendentes do “de cujus”, posto que já terá direito a metade dos bens a título de meação, estando economicamente amparado.

“Entretanto, um aspecto interessante de ressaltar é que mesmo no regime de comunhão universal podem existir bens que não são comuns, mas que pertencem a apenas um dos cônjuges, sendo, portanto, bens particulares” (TARTUCE, SIMÃO, p. 168).

A esse respeito, a doutrina tem afirmado que o cônjuge terá direito a concorrência com os descendentes em relação aos bens particulares, caso não haja patrimônio comum. Assim, em sendo o matrimônio contraído sob o regime de comunhão universal de bens e não havendo bens em comum, havendo somente bens particulares com clausula de incomunicabilidade, como as do art. 1.668 do Código Civil, o cônjuge sobrevivente tocará parte desses bens a título de herança.

Não é outra a opinião de Francisco José Cahali, para quem "haverá de se questionar se terá o viúvo direito sucessório, quando casado no regime da comunhão universal de bens, ou qualquer outro regime convencional, e o falecido possuir apenas bens particulares (p. ex. gravados por cláusula de incomunicabilidade na doação ou por testamento). A coerência recomenda seja deferida a sucessão ao cônjuge sobre os bens particulares, se a estes for restrita a herança do viúvo, a despeito da literalidade do texto ser de diverso conteúdo (TARTUCE, SIMÃO, apud CAHALI, p. 168).

Com este entendimento, mesmo em havendo clausula de incomunicabilidade dos bens particulares do "de cujus”, tal condição não possui validade quando a divisão decorrer da morte, posto que a incomunicabilidade deve ser aplicada apenas quando houver o fim do vinculo matrimonial pelo divórcio.

Verifica-se, portanto, a possibilidade de ocorrência de duas situações quando o regime patrimonial do casamento for o da comunhão universal de bens. Primeiro quando houver bens comuns, hipótese em que não haverá concorrência do cônjuge sobrevivente, tendo este direito apenas a meação; segundo quando não houver bens comuns, sendo que o cônjuge sobrevivente 
terá direito a concorrência sobre os bens particulares do “de cujus”, ainda que gravados com clausula de incomunicabilidade.

Em relação ao regime de comunhão parcial de bens, verifica-se uma maior gama de divisão do patrimônio entre os nubentes, posto que há possiblidade da existência de bens comuns, de bens apenas do marido e bens apenas da mulher. Neste regime, comunicam-se entre os cônjuges os bens adquiridos onerosamente na constância do casamento, excluindo da comunhão os bens particulares, considerando estes como os que cada cônjuge possuía ao se casar e os incomunicáveis constantes no art. 1.659 do Código Civil.

No regime de comunhão parcial de bens, segundo o art. 1.829, I, do Código Civil, o cônjuge concorre com os descendentes quando houver bens particulares. Sob este prisma, a doutrina debate se o cônjuge concorre sobre todo o acervo hereditário ou se apenas em relação aos bens particulares.

Quando não houver bens particulares de cada cônjuge, o sobrevivente não herdará, possuindo direito apenas a meação, sendo este o entendimento consolidado na doutrina e jurisprudência.

Isso porque se não há bens particulares de cada cônjuge, o cônjuge sobrevivente será meeiro da totalidade do que houver, já que a partilha ocorrerá apenas em relação aos bens comuns. A interpretação do art. 1.829, inciso I, do Código Civil, é no sentido de que se o autor da herança não deixou bens particulares, o cônjuge sobrevivente terá direito a sua meação, sendo que a meação do “de cujus” será partilhada exclusivamente entre seus descendentes. Assim, não há que se falar em concorrência sucessória do cônjuge sobrevivente quando o autor da herança não houver deixado bens particulares no regime de comunhão parcial de bens.

No entanto, a questão polêmica que suscita debate na doutrina é em relação à concorrência do cônjuge no regime de comunhão parcial de bens quando o autor da herança houver deixado bens particulares. Atualmente há três correntes doutrinárias a respeito.

Para a primeira corrente, em havendo meação o cônjuge só concorrerá em relação aos bens particulares.

Essa parece ser a mais correta interpretação do dispositivo na opinião dos coautores Flávio Tartuce e José Fernando Simão. Se o regime da comunhão universal de bens não há concorrência em razão da meação existente, com relação à comunhão parcial de bens a concorrência só pode se verificar quanto aos bens particulares, mas jamais com relação aos bens comuns (TARTUCE, SIMÃO, 2008, p. 179). 
Para este entendimento, o cônjuge só concorrerá quanto aos bens particulares, posto que os bens comuns o mesmo é meeiro.

Importante destacar que esta corrente deriva do Enunciado 270, da III Jornada de Direito Civil, organizada pela Justiça Federal, que assim dispõe:

Enunciado 270: Art. 1.829, inc. I, só assegura ao cônjuge sobrevivente o direito a concorrência com os descendentes do autor da herança quando casados no regime da separação convencional de bens, ou, se casados nos regime da comunhão parcial ou participação final nos aquestos, o falecido possuísse bens particulares, hipóteses em que a concorrência se restringe a tais bens devendo os bens comuns (meação) ser partilhados exclusivamente entre os descendentes.

Portanto, pelo enunciado 270, a concorrência do cônjuge sobrevivente restringe-se apenas aos bens particulares do autor da herança, sendo que os bens comuns serão partilhados entre os descendentes.

São adeptos desta corrente Flávio Monteiro de barros, Eduardo de Oliveira Leite, Christiano Cassettari, Francisco José Cahali, Gustavo Rene Nicolau, Jorge Shiguemitsu Fujita, Mario Delgado, Euclides de Oliveira, Sebastião Amorim, Rodrigo da Cunha Pereira, Rolf Madaleno e Zeno Veloso (TARTUCE, SIMÃO, 2008, p. 179).

Se o falecido deixou bens particulares, o cônjuge participa da herança somente a estes bens, excluindo-se os adquiridos na constância do casamento, posto que estes são objetos de meação, em decorrência do regime do matrimonio, e não sucessório. De modo diverso, quando não houver bens particulares deixados pelo "de cujus”, o cônjuge sobrevivente terá direito apenas a meação.

Questão diversa é a hipótese daqueles que defendem que o cônjuge sobrevivente herdará não apenas os bens particulares, mas sim todo o acervo hereditário, fazendo, portanto, com que surja a segunda corrente.

“A posição majoritária, entretanto, não é pacifica e há argumentos favoráveis à ideia de que o cônjuge participaria da sucessão no tocante à totalidade da herança, surgindo aqui a segunda corrente” (TARTUCE, SIMÃO, 2008, p. 180). Para este entendimento, o cônjuge casado sob o regime de comunhão parcial de bens onde houver bens particulares, não recebe 
apenas a sua meação e parte dos bens particulares, mas sim sua meação e parte de todo o acervo hereditário.

Havendo patrimônio particular, o cônjuge sobrevivente receberá sua meação, se casado sob o regime de comunhão parcial de bens, e uma parcela sobre todo o acervo hereditário. Concorre, no nosso entender, em regra, em igualdade de condições com os descendentes do falecido, e tem direito à meação em face do regime matrimonial de bens. Como ocorre, no de comunhão parcial, pois além de receber sua meação, terá um aparte sobre toda a herança. (DINIZ, 2008, p. 124).

Assim, pela segunda corrente, o cônjuge sobrevivente herdará todo o acervo hereditário. Portanto, receberia a meação dos bens comuns, mais uma parcela dos bens particulares e uma parcela da meação que cabia ao “de cujus”.

Ao que parece, esta segunda corrente não é a mais acertada, já que o cônjuge sobrevivente sairia com vantagem excessiva em desfavor dos herdeiros que, muitas vezes, sequer é herdeiro comum de ambos os cônjuges.

Ainda, nítido é o bis in idem nesta segunda corrente, tendo em vista que o cônjuge sobrevivente a ele tocará metade do que já tem, e ainda concorrerá com os descentes na metade dos bens comum pertencente ao “de cujus”. Apenas para frisar, está segunda corrente defende tal forma de entendimento quando houver bens particulares pelo “de cujus”, de modo que ausente estes bens, ao cônjuge sobrevivente tocará apenas a sua meação, em nada tendo que falar em concorrência com os descendentes.

Há quem faça a interpretação invertida das duas correntes anteriores, fazendo, portanto, com que nasça a terceira corrente. Quem defende a interpretação invertida, sustenta que o cônjuge sobrevivente não concorrerá com os descendentes do “de cujus” quando houver bens particulares do morto.

Não se pode olvidar que a regra é a concorrência. Esse direito se sujeita a exceções, limitações de caráter restritivo. O legislador identifica as hipóteses em que o direito é afastado: (1) no regime da comunhão universal de bens e (2) no regime da separação obrigatória. No regime da comunhão parcial, a lei aponta a hipótese em que o direito é assegurado (3): quando houver bens particulares. A ressalva última decorre da duplicidade de situações que este regime contém (existência ou não de bens exclusivos), o que impõe tratamento diferenciado a cada modalidade. Em respeito à natureza mesma do 


\section{O REGIME DE SEPARAÇÃO CONVENCIONAL DE BENS E A NÃO CONCORRÊNCIA DO CÔNJUGE SUPÉRSTITE COM OS DESCENDENTES DO “DE CUJUS”}

regime legal, o direito à concorrência só pode ser deferido se não houver bens particulares no acervo hereditário. (DIAS, 2010).

"Por essa terceira corrente, a concorrência sucessória entre cônjuge e descendentes só ocorre com relação aos bens comuns e não com relação aos bens particulares” (TARTUCE, SIMÃO, 2008, p. 182).

Enquanto os defensores da primeira e da segunda correntes apenas reconheciam, ao cônjuge casado pelo regime de comunhão parcial de bens, o direito á sucessão na hipótese de o falecido ter deixado bens particulares, esta terceira linha de pensamento defende que só há sucessão na hipótese em que ele não os deixou, concorrendo o cônjuge sobrevivente com os descendentes, na herança dos bens comuns. (BRASIL, Superior Tribunal de Justiça, 2009)

Deste modo, no que se refere ao regime de comunhão parcial de bens, há três posicionamentos, sendo que o mais vantajoso ao cônjuge sobrevivente é o da segunda corrente, posto que receberá sua meação e parte de todo o restante do acervo hereditário.

No entanto, no regime de comunhão parcial de bens, entendemos que o posicionamento que traz maior justiça aos descentes é o da primeira corrente, na qual o cônjuge sobrevivente terá a sua meação e concorrerá com os descendentes apenas em relação aos bens particulares, sendo que a meação pertencente aos “de cujus” será partilhada apenas entre os descendentes deste.

Em relação ao regime de participação final nos aquestos, haverá comunicação dos bens apenas no momento da dissolução da sociedade conjugal, sendo que, na constância do casamento, haverá uma separação de bens. Conforme o art. 1.673 do CC, integram o patrimônio próprio os bens que cada cônjuge possuía ao casar e os por ele adquiridos, a qualquer título, na constância do casamento. (TARTUCE, SIMÃO, 2008, p. 184)

A regra de que o cônjuge é herdeiro (CC 1830 e 1845), para os fins do CC 1829 I, se aplica ao cônjuge sobrevivente casado sob o regime da participação final nos aquestos. Morto seu par, o sobrevivente continua titular de seu patrimônio próprio, recebe a meação verificada em virtude do regime de bens adotado (CC 1674 a 1684) e participa como herdeiro necessário da herança deixada pelo morto (CC 1685 c/c 1829 I a III, 1832 a 1835). (JUNIOR, NERY, 2006, p. 987). 
“Como o regime de participação final nos aquestos não esta referido entre as exceções que afastam o direito de concorrência, ao cônjuge sobrevivente é assegurada parcela da herança” (DIAS, 2008, 159).

No entanto, como no regime de participação final dos aquestos existem três massas de bens (bens comuns, bens particular da mulher e bens particular do marido), poderão ocorrer diversas situações na concorrência do cônjuge.

A primeira situação é aquela em que todos os bens deixados pelo cônjuge falecido são bens particulares. Nessa hipótese o cônjuge supérstite não terá direito à participação sobre eles, mas apenas direito sucessório em concorrência com os descendentes.

A segunda esta presente quando todos os bens deixados pelo falecido são bens aquestos. Nessa hipótese o cônjuge supérstite terá direito à participação sobre todos eles em decorrência do regime, mas não terá direito sucessório em concorrência com os descendentes. Havendo participação em vida, não haverá concorrência quando da morte.

Por fim, pode-se falar da situação em que o falecido deixa aquestos em que há participação do cônjuge viúvo e bens particulares em que não há participação. Nesse caso, quanto aos aquestos, em que há participação em razão do regime, não terá o viúvo direito sucessório em concorrência com os descendentes; quanto aos demais bens, como não tem direito á participação, terá a concorrência sucessória (TARTUCE, SIMÃO, 2008, p. 185).

Ademais, importante destacar que o exposto entendimento decorre do já citado Enunciado 270 da III Jornada de Direito Civil da Justiça Federal.

Assim, ocorrendo a situação de haver apenas bens particulares do falecido, o cônjuge terá direito a concorrência com os descendentes, e jamais direito a meação; de outro modo ocorre quando houver apenas bens comuns deixados pelo falecido, nesta hipótese o cônjuge terá direito a meação destes bens, não concorrendo os descendentes quanto a outra parte; no mais, se houver bens comuns e bens particulares deixados pelo “de cujus”, o cônjuge concorrerá quanto a estes bens e terá direito a meação quanto aqueles.

Outro regime adotado pelo Código Civil é o da separação de bens, que pode ser o convencional e a obrigatória. O regime da separação convencional decorre única e exclusivamente da vontade das partes, ao passo que o obrigatório decorre da vontade da Lei (BRASIL, Código Civil, 2002). Para a maioria da doutrina, cada qual desses regimes terão efeitos diferentes no momento da dissolução da sociedade conjugal pela morte.

O regime de separação obrigatória de bens é aquele que decorre da Lei quando os nubentes se encontrarem em uma das situações previstas no art. 1.641, I, II e III, do Código 
Civil. Assim, impõe-se este regime àqueles que convolarem núpcias pendendo causas suspensivas, com pessoa maior de setenta anos e de todos que dependerem para casar de suprimento judicial (BRASIL, Código Civil, 2002).

O regime de separação obrigatória de bens, o cônjuge sobrevivente, em regra, não terá direito a concorrência com os descendentes do “de cujus”.

Não se aplica ao cônjuge sobrevivente, casado sob o regime da separação obrigatória, a regra geral sobre sucessão legítima do cônjuge (CC 180 e 1845), mas sim a exceção do CC 1829 I. Havendo herdeiros descendentes, o cônjuge sobrevivente casado sob o regime de separação obrigatória de bens não é herdeiro necessário. No caso de haver apenas herdeiro ascendente, o cônjuge sobrevivente casado sob o regime de separação obrigatória é herdeiro em concorrência com os mesmos ascendentes do de cujus (CC 1829 II) (JUNIOR, NERY, 2006, p. 987).

No entanto, embora o cônjuge sobrevivente casado sobre o regime de separação obrigatória de bens não tenha direito a concorrência, a Súmula 377 do Supremo Tribunal Federal veio abrandar o dispositivo que impõe este regime. Pela citada súmula, o regime de separação obrigatória de bens transmuda-se para o regime de comunhão parcial de bens. É que no regime de separação obrigatória de bens, comunicam-se os bens adquiridos onerosamente na constância do casamento. “Ainda bem que Súmula do STF alterou este perverso regime para o da comunhão parcial, e a jurisprudência vem declarando a inconstitucionalidade do malsinado dispositivo legal” (DIAS, 2008, p. 156).

Em suma, verifica-se que no ordenamento jurídico brasileiro os efeitos sucessórios em face do cônjuge sobrevivente, quando em concorrência com os descendentes do falecido, terão repercussões diversas, a depender do regime de bens adotado, ora lhe conferindo direito a concorrência, ora denegando este direito. Questão de maior atenção, e que é o tema central do presente trabalho, é a concorrência ou não dos cônjuges casados no regime de separação convencional de bens, a qual merece tópico em separado.

\section{A SUCESSÃO DO CÔNJUGE SOBREVIVENTE NO REGIME DE SEPARAÇÃO CONVENCIONAL DE BENS, DECISÕES DO SUPERIOR TRIBUNAL DE JUSTIÇA E CRITICAS A LUZ DA AUTONOMIA DA VONTADE}


O último regime pesquisado e que é o ponto central do presente artigo é o regime de separação convencional de bens, merecendo tópico próprio, para melhor elucidação.

Pela única e exclusiva interpretação do art. 1.829, I do Código Civil, as exceções a concorrência do cônjuge com os descendentes do “de cujus” são quando o casamento se der pelo regime de comunhão universal de bens, separação obrigatória de bens e comunhão parcial de bens, sendo este quando não houver bens particulares. Nestes citados regimes, o cônjuge ora é apenas meeiro, ora nada recebe.

Para a maioria da doutrina, o cônjuge casado no regime de separação convencional de bens terá direito a concorrência com os descendentes do “de cujus”.

Fica definitivamente superada a questão e não haverá a comunicação de nenhum bem adquirido durante o casamento, se os cônjuges optarem pelo regime de separação convencional de bens. Consequentemente, ao final do casamento, o cônjuge sobrevivente pode ficar desamparado. Não havendo meação, haverá sucessão com os descendentes. (TARTUCE, SIMÃO, 2008, p. 174).

Pensando em proteger o cônjuge sobrevivente, acreditando que o mesmo pode ficar desamparado, alguns doutrinadores são coniventes com o entendimento de que o mesmo deve ser herdeiro em concorrência com os descendentes do “de cujus”, mesmo se casado no regime de separação convencional de bens.

“Havendo herdeiros descendentes, o cônjuge sobrevivente casado sob o regime da separação convencional de bens é herdeiro em concorrência com os mesmos descendentes do de cujus” (JUNIOR, NERY, 2006, p. 987).

Pode-se dizer, portanto, que haverá concorrência do cônjuge sobrevivente com os descendentes do “de cujus” quando o casamento se der pelo regime de participação final nos aquestos, separação convencional de bens e comunhão parcial de bens quando houver bens particulares; por outro lado, não haverá concorrência quando o regime de bens for o de comunhão universal, separação obrigatória e comunhão parcial de bens quando não houver bens particulares.

No entanto, em dezembro de 2009, a Terceira Turma do Superior Tribunal de Justiça, no Recurso Especial n. 992.749/MS, sob a relatoria da Ministra Nancy Andrighi, proferiu entendimento diverso do da doutrina majoritária em relação ao casamento contraído no regime de separação convencional de bens (BRASIL, Superior Tribunal de Justiça, 2009). 


\section{O REGIME DE SEPARAÇÃO CONVENCIONAL DE BENS E A NÃO CONCORRÊNCIA DO CÔNJUGE SUPÉRSTITE COM OS DESCENDENTES DO “DE CUJUS”}

Ao julgar um caso que envolvia herdeiros, cônjuge sobrevivente e regime de bens, o referido Tribunal atendeu os anseios de uma sensata maioria ao determinar não subsistir ao cônjuge casado sob o regime da separação convencional de bens, direito à concorrência sucessória, privilegiando assim a autonomia da vontade privada em detrimento da ordem de vocação hereditária imposta pelo novo diploma civil. (GEROTI, 2010).

Como informado, o casamento sob o regime de separação convencional de bens, segundo a doutrina majoritária, o cônjuge sobrevivente concorre com os descendentes do "de cujus”. No entanto, com o Recurso Especial nº 992.749/MS, da Terceira Turma do Superior Tribunal de Justiça, no ano de 2009 proferiu entendimento no sentido de que, sob pena de acabar com a função do regime de separação convencional de bens, bem como violentar o princípio da dignidade da pessoa humana, sob a ótica da autonomia da vontade, o cônjuge não deveria concorrer em referido regime.

O Tribunal de Justiça de São Paulo (BRASIL, Tribunal de Justiça de São Paulo, 2007) e o Tribunal de Justiça do Estado do Paraná também se pronunciaram no sentido de que o cônjuge sobrevivente casado sob o regime de separação convencional de bens não é herdeiro, portando não deve concorrer. (BRASIL, Tribunal de Justiça do Paraná, 2007).

Porém, a mesma Terceira Turma do Superior Tribunal de Justiça esboçou o entendimento divergente do proferido no Recurso Especial $n^{\circ}$. 992.749/MS, pois no ano de 2015 decidiu que o cônjuge sobrevivente deveria ser herdeiro e concorrer com os descentes nos bens deixados pelo "de cujus”, quando casado no regime de separação convencional de bens, conforme Agravo Regimental no Recurso Especial nº. 1.334.340/MG, de relatoria do Ministro Marco Aurélio Bellizze. (BRASIL, Superior Tribunal de Justiça, 2015).

Ao que se observa, no interior da mesma Turma do Superior Tribunal de Justiça haviam entendimentos em sentido totalmente opostos, o que somente veio a ser pacificado por meio do Recurso Especial n. 1.382.170/SP, de relatoria do Ministro Mauro Ribeiro (BRASIL, Superior Tribunal de Justiça, 2015) . Neste julgado, parece ter ocorrido a pacificação do entendimento, ao afirmar que o cônjuge casado sob o regime de separação convencional de bens é herdeiro, apenas sendo afastando se o regime for o da separação obrigatória de bens, na forma do artigo 1.640 do Código Civil.

Constata-se que, atualmente, prevalece na doutrina e na jurisprudência do Superior Tribunal de Justiça que no regime de separação convencional de bens o cônjuge sobrevivente deve sim ser herdeiro necessário e concorrer com os descendentes do “de cujus”. 
Este entendimento supostamente pacificado pelo Superior Tribunal de Justiça viola frontalmente o princípio da dignidade da pessoa humana e da autonomia da vontade, posto que se em vida os cônjuges optaram pela não comunicabilidade de bens, a lei não deveria na morte interferir em tal escolha.

De fato, a opção paternalista do legislador em equiparar o cônjuge a herdeiro independentemente de ele, no exercício de sua autonomia de vontade, ter optado pela separação absoluta de bens, ocasionou o extermínio do regime da separação convencional de bens na hipótese de falecimento de um dos cônjuges (GEROTI, 2010)

A primeira posição do Superior Tribunal de Justiça, do ano de 2009, de relatoria da Ministra Nancy, parece ser a mais acertada, posto que coaduna com a autonomia da vontade no momento do casamento e nas relação privadas.

Se este entendimento não prevalecer, temos que o legislador, ao mesmo tempo em que “concede com a mão direita o direito de livre escolha sobre o patrimônio no casamento, com a mão esquerda retira a sua eficácia no momento da morte”. (FARIAS, ROSENVALD, 2017, p. 317).

“O legislador, numa demonstração inequívoca de invasão dos limites da autonomia individual por parte da norma jurídica, desvirtuou por completo a essência do regime da separação absoluta”. (GEROTI, 2010).

O grande empecilho encontrado pela doutrina e pelos Tribunais era a respeito da interpretação isolada do indigitado art. 1.829, I, do Código Civil de 2002. O cerne da questão está na interpretação dos dispositivos legais do Código Civil que tratam da ordem de vocação hereditária (artigo 1.829), e do regime da separação de bens entre os cônjuges (artigo 1.687).

O legislador, no art. 1.829, I c/c com art. 1.845 do Código Civil, ao fazer com que o cônjuge sobrevivente seja herdeiro necessário, mesmo casado no regime de separação convencional de bens, contrariou norma que vem desde a época do reinado no Brasil, pois, naquela época, todos os casamentos eram feitos por carta de ametade, salvo quando entre as partes outra coisa for acordada. (MIRANDA, 2001, p. 148). Assim, hodiernamente, parece que o legislador ignorou a vontade das partes, destoando o regime da separação convencional de bens.

Para se chegar à conclusão de que o cônjuge casado no regime de separação convencional de bens não concorre com os descendentes do falecido, deve-se realizar a 


\section{O REGIME DE SEPARAÇÃO CONVENCIONAL DE BENS E A NÃO CONCORRÊNCIA DO CÔNJUGE SUPÉRSTITE COM OS DESCENDENTES DO “DE CUJUS”}

interpretação sistemática dos art. 1.829, I, e do art. 1.687 do Código Civil, conforme asseverou Miguel Reali, bem lembrado por Celina Goes, em artigo publicado pelo IBDFAM.

Assim, somente a análise dos dispositivos legais referente à matéria colocada poderia conduzir à correta interpretação do dispositivo no art. 1.829, I, do Código Civil. Assim, o Professor Miguel Reale, em artigo publicado no jornal “O Estado de São Paulo”, em 12 de abril de 2003, analisou o disposto no art. 1.829, inciso I, do Novo Código Civil, entendendo que tanto o cônjuge casado pelo regime de separação convencional de bens, quanto aquele casado pelo regime de separação obrigatória de bens, não são herdeiros necessários na hipótese de concorrência com os descendentes. A análise do Prof. Reale é baseada no princípio primordial de hermenêutica jurídica, que consiste na interpretação de um artigo em harmonia com os demais contidos naquela codificação. Assim, a análise isolada do art. 1829, I, do Código Civil, pode levar a uma conclusão equivocada; devendo, ao contrário, situar o referido dispositivo no contexto do conjunto das regras relativas à questão examinada. (GOES, 2007).

Para o professor Reali, a interpretação para chegar a conclusão deve ser feita entre os dispositivos da matéria examinada, quais sejam: o de que trata da concorrência do cônjuge e o de que dispõe sobre o regime de separação convencional de bens. Assim, conclui:

Nessa ordem de ideias, duas são as hipóteses de separação obrigatória: uma delas é a prevista no parágrafo único do art. 1.641, abrangendo vários casos; a outra resulta da estipulação feita pelos nubentes, antes do casamento, optando pela separação de bens. A obrigatoriedade da separação de bens é uma consequência necessária do pacto concluído pelos nubentes, não sendo a expressão "separação obrigatória” aplicável somente nos casos relacionados no parágrafo único do art. 1.641. Essa minha conclusão ainda mais se impõe ao verificarmos que - se o cônjuge casado no regime de separação de bens fosse considerado herdeiro necessário do autor da herança - estaríamos ferindo substancialmente o disposto no art. 1.687, sem o qual desapareceria todo o regime separação de bens em razão do conflito inadmissível entre esse artigo e o de n. 1.828, I, fato que jamais poderá ocorrer numa codificação à qual é inerente o princípio da unidade sistemática. (REALI, p. 2).

Ao verificar a obrigatoriedade do regime de separação de bens, deve se ter em mente que esta obrigatoriedade deve ocorrer tanto no regime de separação de bens convencionada por meio de pacto antenupcial, quanto para o regime de separação imposto pela Lei. É que a obrigatoriedade da separação de bens ora decorre da Lei, ora decorre da vontade das partes. 
Esta é a melhor interpretação e a mais justa solução para aqueles que se casam pelo regime da separação total pactuada já que, se as partes pactuaram a separação de bens, muito provavelmente não gostariam que o cônjuge supérstite fosse seu herdeiro em concorrência com os descendentes e, se às partes interessar tal concorrência, poderão fazer doação em vida ao cônjuge ou testamento deixando o disponível para o cônjuge. (GOES, 2007)

Caso o cônjuge casado sob o regime convencional de bens queira assegurar certa parte de seu patrimônio a seu consorte, que faça doação ou testamento da parte disponível da herança. Cabe ao cônjuge utilizar-se desses institutos para deixar bens a seu consorte, quando casado no regime de separação convencional de bens. Não deve o Estado interferir e impor que o cônjuge seja herdeiro necessário no regime de separação convencional, eis que evidente violação a autonomia da vontade.

Se em vida os cônjuges resolveram, de forma voluntaria e livre, adotar o regime de separação total de bens, certamente na morte pretendem que assim seja mantido.

O Código Civil decidiu que os cônjuges casados pelo regime de separação convencional de bens possuem total liberdade na administração de seus bens e separação do patrimônio em vida. Portanto, não cabe ao legislador contrariar o disposto no art. 1.687 do referido diploma legal, afirmando que o cônjuge sobrevivente é herdeiro necessário no regime de separação convencional de bens, ou seja, não cabe ao mesmo misturar os bens no momento da morte.

Ora, se o novo Código Civil, ao disciplinar o regime da separação legal e convencional de bens decidiu pelo total isolamento do patrimônio dos cônjuges, dispensando a outorga uxória e afastando inclusive a comunhão de aquestos, não se pode conceber o entendimento de que cônjuges casados sob o regime de separação voluntária ou convencional de bens seriam herdeiros necessários, concorrendo com os descendentes, sob pena de clara violação ao disposto no art. 1.687 do referido diploma legal (GOES, 2007).

Considerar que o cônjuge sobrevivente casado no regime de separação convencional de bens concorre com os descendentes do falecido, viola o art. 1.687 do Código Civil. De mais a mais, caso os cônjuges casados no regime de separação convencional de bens queiram que um deles seja herdeiro necessário, basta alterar o regime de bens, posto que vigora no Brasil o 


\title{
O REGIME DE SEPARAÇÃO CONVENCIONAL DE BENS E A NÃO CONCORRÊNCIA DO CÔNJUGE SUPÉRSTITE COM OS DESCENDENTES DO “DE CUJUS”
}

princípio da mutabilidade do regime de bens. Logo, se em vida o morto não quis alterar o regime de bens, nem fazer doações ou testamento a seu consorte, não cabe ao legislador impor o cônjuge sobrevivente como herdeiro necessário em concorrência com os descendentes.

Ao Estado não é lícito interferir na vida exclusiva do casal, sob pena de violar o disposto no art. 1.513 do Código Civil, que determina que é vedada a intervenção publica ou privada na comunhão de vida instituída pela família. (BRASIL, Código Civil, 2002).

Além disso, contrariar a vontade dos nubentes no momento da morte viola também o princípio da dignidade da pessoa humana, de onde decorre a autonomia da vontade. "Por tudo isso, a melhor interpretação é aquela que prima pela valorização da vontade das partes na escolha do regime de bens, mantendo-a intacta, assim na vida como na morte dos cônjuges”. (BRASIL, Superior Tribunal de Justiça, 2009).

Uma vez estipulado o regime de casamento como o de separação convencional de bens, esta estipulação deve prevalecer na constância do casamento, bem como em sua dissolução por divórcio ou por morte.

\begin{abstract}
Dessa forma, não remanesce, para o cônjuge casado mediante separação de bens, direito á meação, salvo previsão diversa em pacto antenupcial, tampouco á concorrência sucessória, respeitando-se o regime de bens estipulado, que obriga as partes na vida e na morte. Nos dois casos, portanto, o cônjuge sobrevivente não é herdeiro necessário. Entendimento em sentido diverso suscitaria clara antinomia entre os arts. 1.829 , inc. I, e 1.687 , do CC/02, o que geraria uma quebra da unidade sistemática da lei codificada, e provocaria a morte do regime de separação de bens. Por isso, entre uma interpretação que torna complementares os citados dispositivos, não é crível que seja conferida preferência a primeira solução (BRASIL, Superior Tribunal de Justiça, 2009).
\end{abstract}

$\mathrm{O}$ ato de se convencionar o regime de separação convencional de bens é um ato realizado a dois, o qual o direito sucessório não cabe impor limitações.

Assim, a regra que confere o direito hereditário de concorrência ao cônjuge sobrevivente não alcança nem pode alcançar os que têm e decidiram ter patrimônios totalmente distintos, sob pena de clara violação ao art. 1.687 do CC/02, notadamente quando a incomunicabilidade resulta da estipulação feita pelos nubentes, antes do casamento. (BRASIL, Superior Tribunal de Justiça, 2009) 
Portanto, não deve a Lei infringir a vontade livre estipulada por meio de pacto antenupcial, sob pena de não conferir segurança jurídica aos atos dotados de publicidade oponível “erga omnis".

A intenção dos cônjuges que escolhem, livre e reciprocamente, o regime de separação absoluta é de clareza solar: estabelecer uma relação afetiva sem interseções patrimoniais, apenas afetiva e amorosa. (FARIAS, ROSENVALD, 2017, p. 316).

A gravidade do problema reside em situações na qual o falecido possui filhos exclusivos que não é filho do cônjuge sobrevivente. Nesta situação, adotar que o cônjuge sobrevivente deve concorrer com os filhos exclusivos do falecido, evidentemente altera toda a lógica do sistema. Imagine-se que a viúva também tenha filhos exclusivos. Deste modo, os bens que o cônjuge sobrevivente recebeu em concorrência com os descendentes do falecido será posteriormente transmitido aos seus descendentes exclusivos, que nada tem haver com o proprietário originário.

Veja que a situação certamente gera discórdia, pois que é incompreensível imaginar que pessoa estranha ao afeto e a consanguinidade possa receber o patrimônio que deva pertencer aos herdeiros verdadeiros.

O que causa maior estranheza ao entendimento de que o cônjuge sobrevivente casado no regime de separação convencional de bens deve concorrer, é o fato de se estar diante de relações privadas, na qual o Estado não deve intervir, sendo que toda e qualquer intervenção torna-se absurda e excessiva.

O sentido lógico da existência do regime de separação convencional de bens é justamente o de separar o patrimônio dos consortes, para que cada cônjuge tenha seus bens exclusivamente. Assim, entender que neste regime o cônjuge sobrevivente deva concorrer esvazia e torna inócua a sua adoção, principalmente quando o proprietário do patrimônio já antevia nada deixar para seu consorte.

Com isso, o entendimento favorável a concorrência ignora o regime escolhido voluntariamente pelo casal, afrontando a autonomia da vontade. (FARIAS, ROSENVALD, 2007, p. 322).

O Superior Tribunal de Justiça, no acórdão capitaneado pela Ministra Nancy Andrighi, demonstrou a decisão mais acertada, ao decidir afastar o cônjuge sobrevivente casado sob o regime de separação convencional de bens da concorrência com os descendentes do falecido, posto que entendimento em sentido diverso contraria a sistemática da matéria. Assim, tal 


\section{O REGIME DE SEPARAÇÃO CONVENCIONAL DE BENS E A NÃO CONCORRÊNCIA DO CÔNJUGE SUPÉRSTITE COM OS DESCENDENTES DO “DE CUJUS”}

entendimento esta em consonância com os demais dispositivos legais e principiológicos, merecendo criticas a decisão proferida no Recurso Especial n. 1.552.553/RJ/SP.

A par disto, embora supostamente o Superior Tribunal de Justiça tenha pacificado o entendimento, espera-se que novos casos concretos cheguem em referida Corte, para que ao final possa proferir julgamento coadunado com os princípios da autonomia da vontade, dignidade da pessoa humana e intervenção mínima do Estado nas relação privadas.

\section{CONSIDERAÇÕES FINAIS}

O regime de comunhão parcial de bens traz discuções doutrinárias, sendo que alguns defendem que o cônjuge sobrevivente herdará somente os bens particulares, outros dizem que herdará os bens particulares e a meação do falecido e, ainda, há quem defenda que o cônjuge sobrevivente não herdará caso haja bens particulares do “de cujus”.

No regime de participação final nos aquestos os bens se comunicarão somente no momento da dissolução da sociedade conjugal, sendo que na constância desta vigora verdadeira separação de bens. No entanto, como no regime de participação final dos aquestos existem três massas de bens (bens comuns, bens particular da mulher e bens particular do marido), poderão ocorrer diversas situações na concorrência do cônjuge.

O regime de separação de bens se subdivide em convencnional e obrigatório. O regime de separação obrigatória de bens decorre da Lei quando os nubentes se enquadrarem nas hipoteses do art. 1.641 e incisos, do Código Civil, sendo certo que, neste regime, o cônjuge sobrevivente não receberá nada como herança, possuindo, pela súmula 377 do Supremo Tribunal Federal, direito apenas a parte dos bens adquiridos na constância do casamento. Já o regime de separação convencional de bens deve ser escolhido por meio de pacto antenupcial. Neste regime, parte da doutrina, interpretando o art. 1.829, inciso I, do Código Civil, defende a concorrência do cônjuge sobrevivente com os descendentes do falecido.

O Superior Trbunal de Justiça, no ano de 2009, proferiu entendimento de que cônjuge sobrevivente não deve herdar no regime de separação convencional de bens. Porém, poucos anos depois, o mesmo Tribunal decidiu de forma totalmente oposta ao entendimento anterior, concedendo ao cônjuge sobrevivente o direito a herdar juntamente com os descendentes do "de cujus” no regime de separação convencional de bens. 
O entendimento do Superior Tribunal de Justiça, proferido no Recurso Especial n. 992.749, no sentido de que aqueles que manusearam pacto antenupcial, fazendo a escolha pelo regime de separação convencional de bens, não deverão concorrer com os descendentes do “de cujus”, parece ser o mais acertado, a luz da autonomia da vontade e intervenção minima na relações privadas. Deste modo, o melhor entendimento e que deve ser defendido é o de que o cônjuge sobrevivente que optar pelo regime de separação convencional de bens, nada deve herdar, sendo afastado de qualquer tipo de herança.

Ressalte-se que é o entendimento que se coaduna com a sociedade atual, posto que há casamentos em que os nubentes possuem filhos exclusivos e patrimônio antes das nupcias. Entendimento diverso viola evidentemente o princípio da dignidade da pessoa humana, posto que entre suas vertentes encontra-se o principio da autonomia da vontade. Não cabe ao Estado interferir em regramentos que dizem respeito apenas a vontade dos nubentes, notadamente em se tratando de direitos disponíveis, como é o caso do patrimônio.

Incompreensivel seria a situação da pessoa que contrair nupcias, realizar pacto antenupcial em que estipula o regime de separação convencional de bens e, ao final da vida, ver sua escolha ser desrespeitada por vontade do legislador, o que acarreta verdadeira desistimulação para muitos.

Conferir a concorrência do cônjuge sobrevivente com os descendentes do falecido fará com que o regime de separação convencional de bens deixe de existir, fazendo com que a regra do art. 1.687 e 1.688 se torne letra morta.

Importante ressaltar que, caso o falecido tenha a intenção de contemplar seu parceiro com algum patrimonio, basta o mesmo realizar doações ou pactuar regime de bens diverso do da separação obrigatória.

Há de se atentar que aqueles que pactuam pela separação de bens, terão mais consciência da divisão do patrimônio do que aqueles que são levados a tal situação de forma obrigatória.

Portanto, o que deve prevalecer, a luz da dignidade da pessoa humana, autonomia da vontade e intervenção minima do Estado, é o entendimento de que no regime de separação convencional de bens o cônjuge sobrevivente nada herda. Entendimento diverso deve ser rechaçado. 


\section{REFERÊNCIAS}

AMORIM, Sebastião Luiz. OLIVEIRA, Euclides Benedito de. Inventários e Partilhas: Direito das Sucessões. São Paulo: Universitária de Direito, 2006.

BRASIL. Lei 10.406 de 10 de janeiro de 2002. Institui o Código Civil.

BRASIL, Superior Tribunal de Justiça. Recurso Especial n. 992.749. Relatora Ministra Nancy Andrighi. 21 de dezembro de 2009. Disponível em: http://www.stj.jus.br/SCON/jurisprudencia/doc.jsp?livre=992749\&b=ACOR\&p=true\&t=JUR IDICO\&l=10\&i=7> acesso em 06 de abril de 2018.

BRASIL, Superior Tribunal de Justiça. Recurso Especial n. 1.382.179/SP. Relator Ministro Mauro Ribeiro. 26 de maio de 2015. Disponível em: $<$ http://www.stj.jus.br/SCON/jurisprudencia/doc.jsp?livre=1382170\&b=ACOR\&p=true\&t=J URIDICO\&l=10\&i=9> acesso em 06 de abril de 2018.

BRASIL, Superior Tribunal de Justiça. Recurso Especial n. 1.334.340/MG. Relator Ministro Marcos Aurélio Bellizze. 08 de outubro de 2015. Disponível em: $<$ http://www.stj.jus.br/SCON/jurisprudencia/doc.jsp?livre=1334340\&b=ACOR\&p=true\&t=J URIDICO\&l=10\&i=2> acesso em 06 de abril de 2018.

BRASIL. Tribunal de Justiça do Paraná. Recurso de Agravo de Instrumento n. 0316946-4. Rel. Desembargador Cunha Ribas, 14 de dezembro de 2007. Disponívelem:<http://www.tj.pr.gov.br/portal/judwin/consultas/jurisprudencia/Jurisprudencia Detalhes.asp?Sequencial=1\&TotalAcordaos=1\&Historico=1\&AcordaoJuris=555696>. Acesso em 03 março de 2018.

BRASIL. Tribunal de Justiça d e São Paulo. Recurso de Apelação n. 535.332.4/6-00. Rel. Desembargador Beretta da Silveira, 14 de dezembro de 2007. Disponível.em:<https://esaj.tjsp.jus.br/cjsg/getArquivo.do?cdAcordao=2395835\&vlCaptcha= yhtyb> acesso em 03 de abril de 2018. 
DIAS, Maria Berenice. Manual de direito das sucessões. São Paulo: Revista dos Tribunais, 2008

Ponto Final. Disponível em: < http://www.mariaberenice.com.br/manager/arq/(cod2_785)2_ponto_final.pdf > acesso em 06 de abril de 2018.

DINIZ, Maria Helena. Curso de direito civil brasileiro: direito das sucessões. 22a ed. São Paulo: Saraiva, 2008.

Enunciado 270. III Jornada de Direito Civil. Coordenador Geral Ministro Ruy Rosado de Aguiar. Disponível em:< http://www.cjf.jus.br/enunciados/enunciado/531>. Acesso em 05 de abril de 2018.

FARIAS, Cristiano Chaves, ROSENVALD, Nelson. Curso de Direito Civil: direito das sucessões. $3^{\text {a }}$ ed. Salvador: Juspodivm, 2017.

GEROTI, Caires Cristiane. O cônjuge sobrevivente como herdeiro necessário e a limitação da autonomia da vontade privada. Disponível em: $<$ http://www.ibdfam.org.br/?artigos\&artigo=581> acesso em 24 de maio de 2011.

GOES, Celina de Sampaio. Sucessão: Cônjuge Casado no Regime da Separação de Bens não concorre com descendentes. Disponível em: <http://www.ibdfam.org.br/?artigos\&artigo=313> acesso em 05 de março de 2018.

JUNIOR, N. Nelson. NERY, M. A. Rosa. Código Civil comentado. $4^{\mathrm{a}}$ ed. São Paulo: Revista dos Tribunais, 2006.

NETO, Inácio de Carvalho. Direito sucessório do cônjuge e do companheiro. São Paulo: Método, 2007. 
MIRANDA, Pontes de.Tratado de Direito de Família. Campinas: Bookseller, 2001. p. 148

TARTUCE, Flavio, SIMÂO, José Fernando. Direito civil: direitos das sucessões. $2^{\mathrm{a}}$ ed. São Paulo: Método, 2008.

REALE, Miguel. O Estado de São Paulo: São Paulo, 12 de abril de 2003. 